\title{
Autism Spectrum Disorder Is Associated With Autonomic Underarousal
}

\author{
I. BUJNAKOVA ${ }^{1,2}$, I. ONDREJKA $^{3}$, M. MESTANIK ${ }^{1,2}$, Z. VISNOVCOVA $^{1}$, \\ A. MESTANIKOVA ${ }^{1,2}$, I. HRTANEK $^{3}$, D. FLESKOVA ${ }^{3}$, A. $_{\text {. }}$ CLKOVSKA $^{1,2}$, \\ I. TONHAJZEROVA ${ }^{1,2}$
}

${ }^{1}$ Biomedical Center Martin, Jessenius Faculty of Medicine in Martin, Comenius University in Bratislava, Martin, Slovakia, ${ }^{2}$ Department of Physiology, Jessenius Faculty of Medicine in Martin, Comenius University in Bratislava, Martin, Slovakia, ${ }^{3}$ Psychiatric Clinic, Jessenius Faculty of Medicine in Martin, Comenius University in Bratislava, University Hospital Martin, Slovakia

Received March 22, 2016

Accepted October 26, 2016

\begin{abstract}
Summary
Autism spectrum disorder (ASD) is a serious neurodevelopmental disorder, associated with autonomic dysregulation. However, the pathomechanism leading to autonomic abnormalities is still unclear. The aim of this study was to assess autonomic nervous system (ANS) activity during baseline in homogenous group of autistic children using electrodermal activity (EDA), as an index of sympathetic activity and short-term heart rate variability (HRV) reflecting predominantly cardiac vagal control. Fifteen ASD boys and 15 healthy age-matched boys at the age of 7-15 years were examined. The continuous EDA and ECG were recorded during resting phase in a supine position. Evaluated parameters: EDA amplitude $(\mu S), R R$ interval, spectral power, peak frequency and power spectral density in low (LF-HRV: $0.04-0.15 \mathrm{~Hz}$ ) and highfrequency (HF-HRV: $0.15-0.4 \mathrm{~Hz}$ ) bands of HRV spectral analysis. In ASD group we found significantly shortened RR intervals $(729 \pm 20 \mathrm{~ms}$ vs. $843 \pm 30 \mathrm{~ms}, \mathrm{p}=0.005)$, lower mean EDA $(0.66 \pm 0.13 \mu \mathrm{S}$ vs. $1.66 \pm 0.42 \mu \mathrm{S}, \mathrm{p}=0.033)$, reduced spectral activity and power spectral density in HF-HRV compared to controls $\left(2.93 \pm 0.12 \mathrm{~ms}^{2}\right.$ vs. $3.38 \pm 0.10 \mathrm{~ms}^{2}, \mathrm{p}=0.01 ; 4.12 \pm$ $0.10 \mathrm{~ms}^{2} / \mathrm{Hz}$ vs. $4.56 \pm 0.11 \mathrm{~ms}^{2} / \mathrm{Hz}, \mathrm{p}=0.008$, respectively). We suggest that impairment in resting autonomic regulation associated with ASD could represent an important pathomechanism leading to potential cardiovascular complications in ASD.
\end{abstract}

\section{Key words}

Autism spectrum disorder • Autonomic nervous system • Heart rate variability • Electrodermal activity

\section{Corresponding author}

I. Tonhajzerova, Department of Physiology and Biomedical Center Martin, Jessenius Faculty of Medicine in Martin, Comenius University in Bratislava, Mala Hora 4C, 03601 Martin, Slovak Republic. E-mail: tonhajzerova@jfmed.uniba.sk, ingridtonhajzerova@gmail.com

\section{Introduction}

The autonomic nervous system (ANS) is responsible for maintaining homeostasis, adaptability and physiological flexibility of the organism. Physiologically, both of the sympathetic and parasympathetic systems work at dynamic balance at rest as well as in response to stress. Dysfunction of ANS can lead to a variety of serious problems exhibited in multiple organ systems, such as tachycardia, anxiety, sleep disorders and others (Axelrod et al. 2006, Ming et al. 2011). Moreover, it is assumed that autonomic dysfunction with a broad range of maladaptive conditions is associated with increased risk of cardiovascular adverse outcomes (Thayer and Sternberg 2006, Ming et al. 2011).

Autism spectrum disorder (ASD) is a serious neurodevelopmental disorder that impairs ability of person to communicate and interact with others. Specifically, the core behavioral symptoms in ASD include atypical social and communicative development along with restricted repetitive behaviors, interests and activities. Exact etiology of autism is still unclear, but numbers of new findings clearly show that autism is not a single clinical entity but a behavioral manifestation of 
tens or perhaps hundreds of genetic disorders, influenced additionally by environmental factors (Betancur 2011, Ostatnikova et al. 2015). Abnormal brain structures (the prefrontal lobes, the amygdala, the anterior insular cortex, the anterior cingulate cortex, the cerebellum) have been found in ASD people examined with functional magnetic resonance imaging (fMRI) or in post mortem studies (Courchesne et al. 2001, 2003, Amaral et al. 2008, Schumann et al. 2009, Uddin and Menon 2009). Additionally, the abnormal levels of neurotransmitters or their imbalance of excitation (influence of glutamate, serotonin) and inhibition (GABA effect) in neural circuits complicate entire developmental process in autistic children (Gillberg and Coleman 2000, Purcell et al. 2001, Kelemenova 2010). Thus, existing evidence of structural and functional abnormalities in central nervous system in ASD people may be associated with autonomic dysregulation.

An emerging body of literature suggests the link between ASD symptoms and ANS dysfunction related to sympathetic overarousal, parasympathetic underactivity, or atypical interaction of both systems. Recent research has focused on parasympathetic activity, due to its potential role in regulating emotional and behavioral function (Porges et al. 2013). The findings are inconsistent, including reduced or unaltered parasympathetic activity (Benevides and Lane 2015). Moreover, reduced parasympathetic activity indexed by respiratory sinus arrhythmia (RSA), has been associated with social and emotional difficulties (Porges et al. 2013, Neuhaus et al. 2014), worse language skills (Patriquin et al. 2013), or slower emotion recognition (Bal et al. 2010). On the other side, autistic children with higher RSA amplitude showed better social behavior and cognitive function (Patriquin et al. 2013). Regarding sympathetic activity quantified by electrodermal activity (EDA), existing findings in ASD are mixed, such as increased (Kushki et al. 2013, O'Haire et al. 2015) and unaltered (Levine et al. 2012, Legiša et al. 2013) basal skin conductance, as well as atypical EDA reactivity to faces (Hirstein et al. 2001) or eye contact (Kylliäinen and Hietanen 2006).

Based on these studies, we addressed the hypothesis that ASD children are characterized by altered autonomic activity. Therefore, the aim of this study was to assess resting activity of the autonomic nervous system in children suffering from autism spectrum disorder using electrodermal activity and spectral analysis of heart rate variability that is not sufficiently described in ASD.

\section{Methods}

\section{Participants}

We examined 15 children (males aged 7-15, mean age $11.3 \pm 0.5$ years, BMI $18.9 \pm 0.8 \mathrm{~kg} / \mathrm{m}^{2}$ ), diagnosed with Asperger syndrome $(\mathrm{n}=11)$ or with highfunctioning autism $(n=4)$. The patients were recruited from Psychiatric Clinic at the University Hospital in Martin and from Regional Autism Centre in Žilina. Inclusion criteria used for enrolling children for the ASD group were: primary ASD diagnosis, IQ above 70, ability to perform the study and body mass index (BMI) calculated for age growth (in order to exclude obesity, overweight or underweight). The ASD diagnosis was assessed by child and adolescent psychiatrist according to DSM-IV-TR and DSM-5 (American Psychiatric Association 2000, 2013). Diagnosis was consecutively confirmed by supervised qualified specialist in child and adolescent psychiatry prior to inclusion of the ASD patients in this study. Five autistic children suffered from comorbid attention-deficit/hyperactivity disorder (ADHD), but the ADHD symptoms - hyperactivity, impulsivity and inattention - were not clinically manifest at the time of examination. Furthermore, absence of any psychiatric symptoms and other comorbid mental disorders in ASD group was confirmed by supervised qualified specialist in child and adolescent psychiatry according to DSM-5 diagnostic criteria prior to examination on the same day. Importantly, the ASD patients were specially instructed for the examination to avoid potential stress and anxious effect.

The intellectual functioning, measured by Wechsler Intelligence Scale for Children (WISC III) was conducted by a licensed practitioner - clinical psychologist. Full scale IQ scores were above 80 . Medications potentially influencing autonomic nervous system were administered last time $24 \mathrm{~h}$ before examination.

The age and gender-matched control group $(n=15)$ was examined. The participants were volunteers recruited through advertising at nearby schools and had no history of mental and neurodevelopmental disorders and had normal school performance. Exclusion criteria for both groups were following: acute infection, cardiovascular, endocrine, respiratory disease or mental and other disease potentially influencing ANS (obesity, underweight, alcohol or drug abuse). All control children were healthy without taking of any medications. Basic groups' characteristics are presented in Table 1. 
Table 1. The characteristics of studied groups.

\begin{tabular}{|c|c|c|c|}
\hline & Controls $(n=15)$ & $\operatorname{ASD}(n=15)$ & $p$-value \\
\hline Age (years) & $11.1 \pm 0.5$ & $11.3 \pm 0.5$ & 0.800 \\
\hline$H R(b p m)$ & $72.1 \pm 2.5$ & $83.0 \pm 2.3$ & 0.004 \\
\hline$S B P(m m ~ H g)$ & $96.5 \pm 2.5$ & $99.7 \pm 2.8$ & 0.394 \\
\hline$D B P(m m ~ H g)$ & $51.9 \pm 2.1$ & $58.5 \pm 2.6$ & 0.062 \\
\hline$B M I\left(\mathrm{~kg} / \mathrm{m}^{2}\right)$ & $18.0 \pm 0.8$ & $18.9 \pm 0.8$ & 0.178 \\
\hline Weight $(\mathrm{kg})$ & $41.0 \pm 3.6$ & $43.7 \pm 3.4$ & 0.578 \\
\hline \multirow[t]{2}{*}{$W H R$} & $0.80 \pm 0.01$ & $0.84 \pm 0.01$ & 0.007 \\
\hline & & ADHD (5) & \\
\hline \multirow[t]{3}{*}{ Comorbidities } & - & selective mutism (1) & \\
\hline & & allergy (1) & \\
\hline & & atomoxetine (2) & \\
\hline \multirow{3}{*}{ Medication } & & methylphenidate (2) & \\
\hline & - & valproate (1) & \\
\hline & & desloratadine (1) & \\
\hline
\end{tabular}

ASD - autism spectrum disorder, HR - heart rate, bpm - beats per minute, SBP - systolic blood pressure, DBP - diastolic blood pressure, WHR - waist to hip ratio, BMI - body mass index, ADHD - attention deficit/hyperactivity disorder. Values are expressed as mean \pm SEM. Probability $\mathrm{p}<0.05$ was considered as significant.

\section{Ethics statement}

The study was approved by the Ethics Committee of the Jessenius Faculty of Medicine in Martin, Comenius University in Bratislava in accordance with the Declaration of Helsinki (2000) of the World Medical Association. All children and their guardians were carefully informed about the study protocol and informed written consent was obtained.

\section{Protocol}

All the children were examined under standard conditions between 8:00 am and 12:30 pm in a quiet room with temperature of 22 to 24 degrees. Light breakfast $1 \mathrm{~h}$ before examination was recommended. After mean heart rate evaluation, blood pressure measurement by auscultatory method and anthropometric examination using InBody 120 (Biospace Co., Ltd., Korea), they were instructed to remain in sitting position for the initial phase necessary to avoid the potential stress effect. The sensors for physiological measurement were placed on the child's fingers (EDA sensors) and chest (ECG sensor). Then they were instructed to lie down and remain for $5 \mathrm{~min}$ without speaking and movement to stabilize the ANS. Subsequently, EDA and HRV were recorded continuously during a 5-min rest period.

\section{Physiological measures}

Electrodermal activity is considered as a sensitive marker of sympathetic cholinergic nervous system. EDA was continuously recorded using device FlexComp Infiniti (Thought Technology Ltd., Canada) applying a constant electrical voltage between two electrodes, usually strapped to two fingers of one hand. Two SC-Flex/Pro sensors (dry $\mathrm{Ag} / \mathrm{AgCl}$ electrodes) were attached to the palmar surface of the medial phalanges of the second and fourth digits of non-dominant hand and fastened using velcro straps. This allows measurement of skin conductance level, which vary with sweat gland activity due to stress or emotional excitement. The sensors sampled signals at the rate of 2048 samples/s and passed data to the host computer via the microprocessorcontrolled FlexComp Infiniti encoder unit for subsequent analysis. Responses contaminated by children's body movements were easily distinguished on the output trace and excluded from the analysis. Mean EDA level $(\mu S)$ was evaluated as the skin conductance amplitude averaged in baseline phase.

Heart rate variability: The ECG signal was recorded using the telemetric diagnostic system DiANS PF8 (DIMEA Group, Ltd., Czech Republic). Continuous recording of $\mathrm{RR}$ intervals was performed with sampling frequency of $1 \mathrm{kHz}$. The time phase was $5 \mathrm{~min}$, according to recommendations of Task Force (1996) for short-term HRV analysis enabling evaluation of the sympathovagal balance changes. Before spectral analysis, transmitted data were visually checked and any artifacts were 
removed manually. Then, data were evaluated by using the Fast Fourier Transform (FFT) method (using a window length of 256 samples) with partly modified CGSA (Coarse-graining Spectral Analysis) procedures (Yamamoto and Hughson 1991). The linear (spectral) analysis of HRV provides quantification of heart rate oscillations and allows to evaluate the faster high frequency (HF: $0.15-0.4 \mathrm{~Hz}$ ) component, primarily influenced by vagal activity, and slower low frequency (LF: 0.04-0.15 Hz) component reflecting both cardiaclinked sympathetic and parasympathetic activity mediated through baroreflex (Task Force 1996). Evaluated HRV parameters: RR interval (ms), spectral power in low frequency band (LF-HRV in $\mathrm{ms}^{2}$ ) and high frequency band (HF-HRV in $\mathrm{ms}^{2}$ ), peak frequency in low frequency band (freqLF-HRV in $\mathrm{Hz}$ ) and high frequency band (freqHF-HRV in $\mathrm{Hz}$ ), power spectral density in low frequency band (PSD LF-HRV, $\mathrm{ms}^{2} / \mathrm{Hz}$ ) and high frequency band (PSD HF-HRV, $\mathrm{ms}^{2} / \mathrm{Hz}$ ). Importantly, spectral activity in the high frequency band (HF-HRV: $0.15-0.4 \mathrm{~Hz}$ ) is accepted as an index of cardiac vagal control (Task Force 1996).

\section{Statistical analysis}

Statistical analysis was accomplished using the statistical software MYSTAT 12 for Windows 2008 (SSI, Richmond, CA, USA). Absolute values of HRV parameters - LF-HRV, HF-HRV, PSD LF-HRV and PSD HF-HRV - differed greatly among individuals, therefore, they were logarithmically transformed for next statistical analysis. The non-gaussian/gaussian distribution was ascertained by Shapiro-Wilk normality test. The Kruskal Wallis nonparametric test was used for data with nongaussian distribution and unpaired Student's t-test was used for variables with gaussian distribution. A value of $\mathrm{p}<0.05$ was considered as significant. Data were expressed as the mean $\pm \mathrm{SEM}$.

\section{Results}

\section{Cardiovascular parameters}

The mean heart rate was significantly higher in ASD group compared to controls $(83.0 \pm 2.3 \mathrm{bpm}$ vs. $72.1 \pm 2.5 \mathrm{bpm}, \mathrm{p}=0.004)$. Systolic and diastolic blood pressure was without significant between-group differences (Table 1).

\section{EDA magnitude}

The EDA individual values for each subject from studied groups are presented in the Figure 1A. Statistical analysis revealed that resting mean amplitude of electrodermal activity was significantly lower in the ASD $(0.66 \pm 0.13 \mu \mathrm{S}$ vs. $1.66 \pm 0.42 \mu \mathrm{S}, \quad \mathrm{p}=0.033)$ compared to controls (Fig. 1B).

\section{HRV parameters}

RR interval was significantly shortened in ASD group compared to controls $(729 \pm 20 \mathrm{~ms}$ vs. $843 \pm 30 \mathrm{~ms}$, $\mathrm{p}=0.005)$.

The logHF-HRV individual values for each subject from studied groups are presented in the Figure $2 \mathrm{~A}$. With respect to vagal activity, the logHF-HRV during baseline was significantly lower $\left(2.93 \pm 0.12 \mathrm{~ms}^{2}\right.$ vs. $3.38 \pm 0.10 \mathrm{~ms}^{2}, \mathrm{p}=0.01$, Fig. 2B) and the $\log \mathrm{PSD}$ HF-HRV was significantly decreased in the ASD group compared to control group $\left(4.12 \pm 0.10 \mathrm{~ms}^{2} / \mathrm{Hz}\right.$ vs. $4.56 \pm 0.11 \mathrm{~ms}^{2} / \mathrm{Hz}, \mathrm{p}=0.008$, Table 2). No significant differences were found in other HRV parameters. All HRV parameters are noted in the Table 2.
A

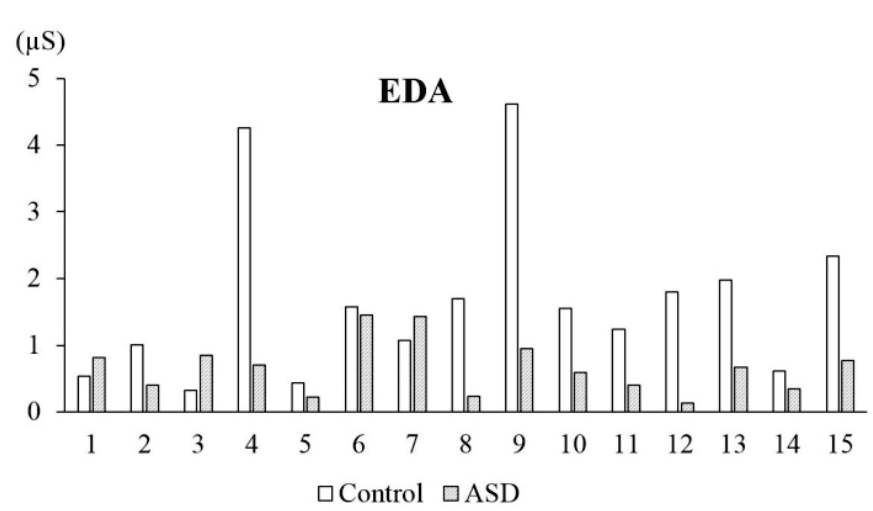

B

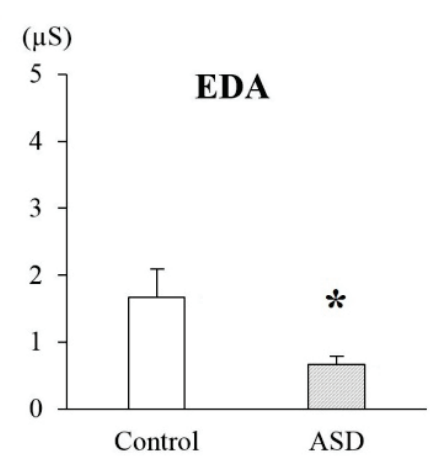

Fig. 1. Electrodermal activity (EDA) during rest: A) The individual values of EDA in control group (white bars) and children suffering from autism spectrum disorder (ASD) (shaded bars). B) Mean EDA in control group and children suffering from autism spectrum disorder (ASD). * p $<0.05$. 
A

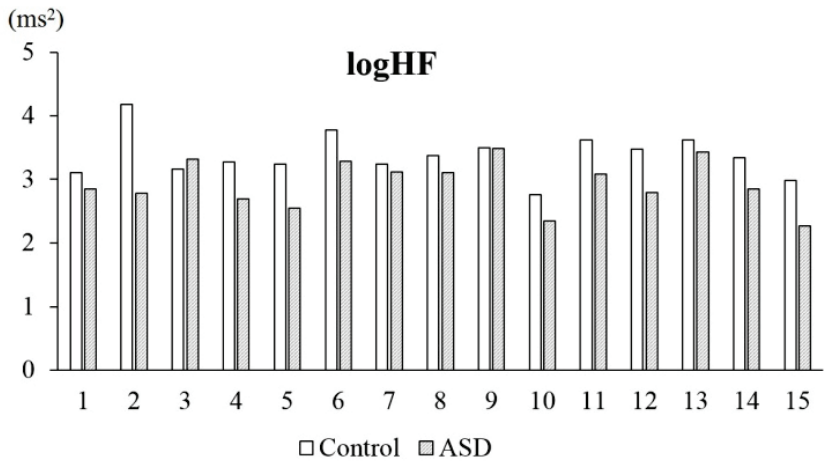

B

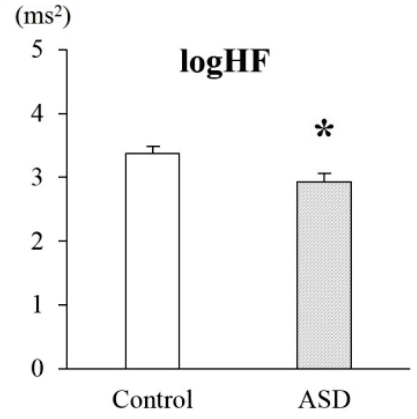

Fig. 2. The high frequency band of heart rate variability (logHF-HRV): A) The individual values of logHF in control group (white bars) and children suffering from autism spectrum disorder (ASD) (shaded bars). B) Mean values of logHF in control group and children suffering from autism spectrum disorder (ASD). * $p<0.05$.

Table 2. HRV parameters in ASD and control group.

\begin{tabular}{lccc}
\hline & $\begin{array}{c}\text { Controls } \\
(\mathbf{n}=\mathbf{1 5})\end{array}$ & $\begin{array}{c}\text { ASD } \\
(\mathbf{n}=\mathbf{1 5})\end{array}$ & $\boldsymbol{p}$-value \\
\hline RR interval $(\mathrm{ms})$ & $843 \pm 30.0$ & $729 \pm 20.0$ & 0.005 \\
$\log L F-H R V\left(\mathrm{~ms}^{2}\right)$ & $2.76 \pm 0.12$ & $2.66 \pm 0.12$ & 0.561 \\
$\log H F-H R V\left(\mathrm{~ms}^{2}\right)$ & $3.38 \pm 0.10$ & $2.93 \pm 0.12$ & 0.010 \\
freqLF-HRV $(H z)$ & $0.10 \pm 0.01$ & $0.10 \pm 0.01$ & 0.992 \\
freqHF-HRV $(H z)$ & $0.26 \pm 0.02$ & $0.28 \pm 0.02$ & 0.542 \\
$\log P S D L F-H R V$ & $4.35 \pm 0.12$ & $4.17 \pm 0.11$ & 0.253 \\
$\left(m s^{2} / H z\right)$ & & & \\
$\log P S D H F-H R V$ & $4.56 \pm 0.11$ & $4.12 \pm 0.10$ & 0.008 \\
$\left(m s^{2} / H z\right)$ & & & \\
\hline
\end{tabular}

HRV - heart rate variability, ASD - autism spectrum disorder, logLF-HRV - spectral power in low frequency band logarithmically transformed $(0.04-0.15 \mathrm{~Hz})$, logHF-HRV - spectral power in high frequency band logarithmically transformed $(0.15-0.4 \mathrm{~Hz})$, freqLF-HRV - the peak frequency in the low frequency band, freqHF-HRV - the peak frequency in the high frequency band, logPSD LF-HRV - power spectral density of the low frequency band logarithmically transformed, logPSD HF-HRV - power spectral density of the high frequency band logarithmically transformed. Values are expressed as mean $\pm \mathrm{SEM}$. The probability $\mathrm{p}<0.05$ was considered as significant.

\section{Discussion}

In this study, we assessed autonomic activity in group of autistic children using autonomic indices: electrodermal activity (EDA), such as a sympathetic index and short-term heart rate variability (HRV), which is predominantly mediated by cardiac vagal control. Our results found tachycardia, lower HRV indices (logHF-HRV, logPSD HF-HRV) and decreased EDA indicating impaired both sympathetic and cardiovagal regulation at rest in ASD children.
Autism is characterized by complex social, behavioral and communicational impairment. In addition to the neurodevelopmental symptoms, children with ASD seem to suffer more frequently from cardiovascular dysregulation manifested by cold extremities, altered peripheral perfusion, syncope, and exaggerated heart rate and blood pressure responses to stress (Palkovitz and Wiesenfeld 1980, Ming et al. 2005, Axelrod et al. 2006, Ming et al. 2016). In particular, increased heart rate was repeatedly found in children with ASD compared to typically developing controls under resting conditions as well as during mental stress (e.g. Kushki et al. 2013, Porges et al. 2013). With respect to central-peripheral autonomic pathways, the altered cardiovascular regulation seems to be predominantly mediated by parasympathetic system, specifically the reduced cardiovagal control at rest and in response to stress, and lower cardiac sensitivity to baroreceptor reflex (Benevides and Lane 2015, Klusek et al. 2015, Ming et al. 2016). Regarding the sympathetic cardiac regulation, the studies examining beta-adrenergic activation indexed by pre-ejection period did not find significant differences between autistic children and typically developing controls at rest (Schaaf et al. 2015, Neuhaus et al. 2016). However, children with ASD showed increased sympathetic activity indexed by pre-ejection period during social interaction with familiar person, whereas typically developing children were characterized by decrease of sympathetic influence (Neuhaus et al. 2016). From this context, detailed study of the central regulatory effects on peripheral organs could help to understand complex abnormalities of autonomic control mechanisms in children with ASD.

The cardiac function is extremely sensitive to autonomic regulatory outputs (Beauchaine 2001). 
Spontaneous heart rate "beat-to-beat" oscillations, i.e. heart rate variability (HRV), represent the highly integrated cardiac neural control and the HRV analysis symbolizes a noninvasive window into complex cardiac chronotropic regulation (Calkovska and Javorka 2008, Tonhajzerova et al. 2011, Tonhajzerova et al. 2012). Our findings of cardiovagal decreased modulation are consistent with most previous studies reported decreased vagal cardiac regulation in ASD (Ming et al. 2005, Bal et al. 2010, Porges et al. 2013, Neuhaus et al. 2014). Therefore, higher heart rate found in our ASD group could reflect cardiac-linked parasympathetic underactivity (indexed by lower logHF-HRV and logPSD HF-HRV) rather than dominance of cardiac-linked sympathetic activity. In this context, on the other side, electrodermal activity as a sensitive physiological marker of sympathetic cholinergic system regulated the activity of sweat glands (Dawson et al. 2000, Vetrugno et al. 2003) was reduced in ASD children. These findings of sympathetic underarousal indicating potential deficit in sympathetic cholinergic modulation in ASD are in contrast with most previous studies showing increased or unaltered amplitude of mean EDA in ASD (Levine et al. 2012, Kushki et al. 2013, Legiša et al. 2013, O'Haire et al. 2015).

The neurophysiological mechanisms leading to atypical EDA and HRV pattern related to ASD are still unexplored. Benarroch (1993) described the central autonomic network as highly integrated system, regulating visceromotor, neuroendocrine, and behavioral responses that are critical for physiological adaptability. The mechanisms of autonomic regulation, specifically of cardiac vagal control are complicated by the large number of cortical, subcortical and brainstem structures such as prefrontal cortex, anterior cingulate cortex, hypothalamus, amygdala or nucleus of the solitary tract. Similarly, central control of EDA, with excitatory and inhibitory influences on the sympathetic nervous system, includes two main distinct groups of structures: limbichypothalamic, related to emotions and thermoregulation and premotor-basal ganglia, related to preparation for motor movements. The hypothalamus is considered as main integrative structure of ANS control (Dawson et al. 2000, Boucsein 2012). Importantly, structures as prefrontal cortex, anterior cingulate cortex and amygdala, involved in regulation of both cardiac vagal control and skin conductance, are considered as abnormal in autistic children (Brambilla et al. 2003, Amaral et al. 2008, Schumann et al. 2009, Stoner et al. 2014).
In particular, the amygdala is regarded as a neuropathological marker in autism research, given its established role in the regulation of emotions and social behavior (Schumann et al. 2009) and due to its extensive connections with hypothalamus and ventromedial prefrontal cortex (vmPFC), amygdala is significantly implicated in central autonomic control (Critchley 2002, Arnsten 2009). Physiologically, the amygdala, which becomes active during threat/uncertainty, is under tonic inhibitory control from the prefrontal cortex. Thus, in case of threat or novelty, the prefrontal cortex becomes hypoactive. This hypoactive state is related to disinhibition of sympathoexcitatory defensive circuits and inhibition of parasympathoexcitatory neurons accompanied by an increase in heart rate (HR) and decrease of vagally mediated HRV (Hänsel and von Känel 2008, Thayer and Lane 2009). Moreover, the sympathetic branch activity is under tonic inhibitory control via GABAergic mediated projections from the prefrontal cortex (Thayer and Lane 2009). In addition, the importance of inhibitory processes by prefrontal cortex is essential to the preservation of the integrity of the system (Thayer and Sternberg 2006).

In ASD children, the amygdala is initially larger than normal and adult size reaches before adolescence. This abnormal growth trajectory of amygdala seems to be related with severity of social and communication impairments in ASD (Sparks et al. 2002, Schumann et al. 2004, Schultz et al. 2005, Amaral et al. 2008, Schumann et al. 2009). Moreover, Schumann et al. (2004) assumed that although amygdala of older autistic children is approximately the same size as older typically developing children, its neuroanatomical or functional organization seems to be different in ASD. Thus, the amygdala role in regulation of HRV and EDA in autistic children is more complicated and still discussed.

The abnormalities of the prefrontal cortex, such as minicolumnar pathology (Casanova et al. 2006), or abnormal laminar cytoarchitecture (Stoner et al. 2014), confirmed our assumption that prefrontal cortex underactivity could be associated with reduced HRV and EDA in autism. Importantly, Courchesne and Pierce (2005) clarified that connectivity within frontal lobe in ASD is excessive and disorganized, whereas connectivity between frontal cortex and other systems is reduced. Therefore, it is suggested that aberrant brain connectivity would impair the basic frontal function of integrating information from widespread systems resulting in altered autonomic activity in ASD (Courchesne and Pierce 
2005). We assume that differences in neuroanatomy, function and connectivity in these regions may affect sympathetic as well parasympathetic function in ASD children quantified by EDA and HRV, respectively.

From this context, symptoms of anxiety in autism were assumed to be associated with lower functional connectivity between frontal cortex and limbic system, as an impaired frontal inhibition of limbic system (Wang et al. 2016). Interestingly, Panju et al. (2015) studied two groups of ASD (low-anxiety and highanxiety) and they found significantly decreased mean EDA in high-anxiety ASD group. Lower sympathetic activity was found also in several mental disorders such as ADHD or depression (Dawson et al. 2000, Snoek et al. 2004). Our study revealed sympathetic underactivity indexed by lower EDA in ASD as a result of potential abnormalities in cortical and subcortical regulatory areas associated with autistic children. However, it is questionable whether our findings of altered autonomic activity are predominantly related to autism-linked abnormal central autonomic control or it could reflect potential subclinical and asymptomatic comorbid psychiatric symptoms associated with autism (e.g. anxiety).

With regard to cardiac vagal control, polyvagal theory (Porges 1995, 2003, Porges et al. 2013) reported that myelinated vagus is a dynamic contributor to the processes of the emotion and social interaction. Functionally, the "vagal brake" by modulating visceral state (slowing or speeding heart rate) enables the individual to promptly engage and disengage with objects and to support self-soothing and calm behavioral states. It seems that higher cardiac vagal control is associated with better social behavior and cognitive function; however, these cardiovagal patterns are specifically compromised in autism (Porges 2003). Therefore, lower cardiac vagal regulation found in our ASD children may indicate a less effective "vagal brake" associated with deficits in behavioral and psychological features of the social engagement system. Moreover, the impaired cardiac vagal regulation in autistic children could refer to worse language skills and deficits in social, emotional regulation.

\section{Limitations of the study}

This study included a relatively small group of children suffering from ASD, therefore, further validation in larger sample size of autistic children is needed. Furthermore, cardiac autonomic activity has been affected by specific medication as methylphenidate (Kim et al. 2015). Despite the fact that we do not assume a significant treatment effect on the studied autonomic parameters due to small sample of treated autistic children and exclusion of treatment before the examination in this study, a comparison between treated and non-treated ASD patients might clarify this crucial issue in future studies.

In this study, clinical measures of anxiety or other psychiatric symptoms by special scales were not evaluated in ASD patients. We assume that the interaction between psychiatric symptoms and ASD-linked abnormal autonomic activity could illuminate the pathway linking sympathovagal imbalance and autism. Moreover, the ANS function was examined only during resting phase. From this point of view, autonomic reactivity in response to physiological or mental stress might bring more information about autonomic regulatory mechanisms in ASD. Further research in these fields is needed.

\section{Conclusion}

This study revealed both sympathetic and parasympathetic lower resting activity indicating autonomic underarousal in ASD children. We assume that the assessment of early and subclinical symptoms of impaired complex neurocardiac regulation could elucidate potential pathomechanism leading to cardiovascular and other complications associated with ASD.

\section{Conflict of Interest}

There is no conflict of interest.

\section{Acknowledgements}

This work was supported by VEGA 1/0087/14 and the project „Biomedical Center Martin“ ITMS code: 26220220187, co-financed from EU sources.

\section{References}

AMARAL DG, SCHUMANN CM, NORDAHL CW: Neuroanatomy of autism. Trends Neurosci 31: 137-145, 2008. AMERICAN PSYCHIATRIC ASSOCIATION: Diagnostic and Statistical Manual of Mental Disorders DSM IV-TR (Text Revision), $4^{\text {th }}$ ed., American Psychiatric Association, Washington D.C., 2000, 943 pp. 
AMERICAN PSYCHIATRIC ASSOCIATION: Diagnostic and Statistical Manual of Mental Disorders DSM-5, $5^{\text {th }}$ ed., American Psychiatric Association, Arlington, 2013, pp 50-59.

ARNSTEN AF: Stress signalling pathways that impair prefrontal cortex structure and function. Nat Rev Neurosci 10: 410-422, 2009.

AXELROD FB, CHELIMSKY GG, WEESE-MAYER DE: Pediatric autonomic disorders. Pediatrics 118: 309-321, 2006.

BAL E, HARDEN E, LAMB D, VAN HECKE AV, DENVER JW, PORGES SW: Emotion recognition in children with autism spectrum disorders: relations to eye gaze and autonomic state. J Autism Dev Disord 40: 358-370, 2010.

BEAUCHAINE T: Vagal tone, development, and Gray's motivational theory: toward an integrated model of autonomic nervous system functioning in psychopathology. Dev Psychopathol 13: 183-214, 2001.

BENARROCH EE: The central autonomic network: functional organization, dysfunction, and perspective. Mayo Clin Proc 68: 988-1001, 1993.

BENEVIDES TW, LANE SJ: A review of cardiac autonomic measures: considerations for examination of physiological response in children with autism spectrum disorder. J Autism Dev Disord 45: 560-575, 2015.

BETANCUR C: Etiological heterogeneity in autism spectrum disorders: more than 100 genetic and genomic disorders and still counting. Brain Res 1380: 42-77, 2011.

BOUCSEIN W: Electrodermal Activity. Springer, New York, 2012, pp 39-42.

BRAMBILLA P, HARDAN A, DI NEMI SU, PEREZ J, SOARES JC, BARALE F: Brain anatomy and development in autism: review of structural MRI studies. Brain Res Bull 61: 557-569, 2003.

CALKOVSKA A, JAVORKA K: Neural regulation of the heart and heart rate variability. In: Heart Rate Variability Mechanisms, Evaluation and Clinical Utilization (in Slovak). K JAVORKA (ed), Osveta, Martin, 2008, pp 16-19.

CASANOVA MF, VAN KOOTEN IA, SWITALA AE, VAN ENGELAND H, HEINSEN H, STEINBUSCH HW, HOF PR, TRIPPE J, STONE J, SCHMITZ C: Minicolumnar abnormalities in autism. Acta Neuropathol 112: 287-303, 2006.

COURCHESNE E, PIERCE K: Why the frontal cortex in autism might be talking only to itself: local over-connectivity but long-distance disconnection. Curr Opin Neurobiol 15: 225-230, 2005.

COURCHESNE E, KARNS CM, DAVIS HR, ZICCARDI R, CARPER RA, TIGUE ZD, CHISUM HJ, MOSES P, PIERCE K, LORD C, LINCOLN AJ, PIZZO S, SCHREIBMAN L, HAAS RH, AKSHOOMOFF NA, COURCHESNE RY: Unusual brain growth patterns in early life in patients with autistic disorder: an MRI study. Neurology 57: 245-254, 2001.

COURCHESNE E, CARPER R, AKSHOOMOFF N: Evidence of brain overgrowth in the first year of life in autism. JAMA 290: 337-344, 2003.

CRITCHLEY HD: Electrodermal responses: what happens in the brain. Neuroscientist 8: 132-142, 2002.

DAWSON M, SCHELL A, FILION D: The electrodermal system. In: Handbook of Psychophysiology. JT CACIOPPO, LG TASSINARY, GG BERNTSON (eds), Cambridge University Press, New York, 2000, pp 200-223.

GILLBERG C, COLEMAN M: The disease entities of autism. In: The Biology of Autistic Syndromes. C GILLBERG, M COLEMAN (eds), MacKeith Press, London, 2000, pp 118-135.

HÄNSEL A, VON KÄNEL R: The ventro-medial prefrontal cortex: a major link between the autonomic nervous system, regulation of emotion, and stress reactivity? Biopsychosoc Med 2: 21, 2008.

HIRSTEIN W, IVERSEN P, RAMACHANDRAN VS: Autonomic responses of autistic children to people and objects. Proc R Soc Lond B Biol Sci 268: 1883-1888, 2001.

KELEMENOVA S: Neurotransmitters and neuroproteins in etiology of autism. In: Autism in the Perspective of Neuropsychobiology (in Slovak). D OSTATNIKOVA (ed), Comenius University, Bratislava, 2010, pp 173-190.

KIM HJ, YANG J, LEE MS: Changes of heart rate variability during methylphenidate treatment in attention-deficit hyperactivity disorder children: a 12-week prospective study. Yonsei Med J 56: 1365-1371, 2015.

KLUSEK J, ROBERTS JE, LOSH M: Cardiac autonomic regulation in autism and Fragile X syndrome: a review. Psychol Bull 141: 141-175, 2015. 
KUSHKI A, DRUMM E, PLA MOBARAK M, TANEL N, DUPUIS A, CHAU T, ANAGNOSTOU E: Investigating the autonomic nervous system response to anxiety in children with autism spectrum disorders. PLoS One 8: e59730, 2013.

KYLLIÄINEN A, HIETANEN JK: Skin conductance responses to another person's gaze in children with autism. $J$ Autism Dev Disord 36: 517-525, 2006.

LEGIŠA J, MESSINGER DS, KERMOL E, MARLIER L: Emotional responses to odors in children with highfunctioning autism: autonomic arousal, facial behavior and self-report. J Autism Dev Disord 43: 869-879, 2013.

LEVINE TP, SHEINKOPF SJ, PESCOSOLIDO M, RODINO A, ELIA G, LESTER B: Physiologic arousal to social stress in children with autism spectrum disorders: a pilot study. Res Autism Spectr Disord 6: 177-183, 2012.

MING X, JULU PO, BRIMACOMBE M, CONNOR S, DANIELS ML: Reduced cardiac parasympathetic activity in children with autism. Brain Dev 27: 509-516, 2005.

MING X, BAIN JM, SMITH D, BRIMACOMBE M, GOLD VON-SIMSON G, AXELROD FB: Assessing autonomic dysfunction symptoms in children: a pilot study. J Child Neurol 26: 420-427, 2011.

MING X, PATEL R, KANG V, CHOKROVERTY S, JULU PO: Respiratory and autonomic dysfunction in children with autism spectrum disorders. Brain Dev 38: 225-232, 2016.

NEUHAUS E, BERNIER R, BEAUCHAINE TP: Brief report: social skills, internalizing and externalizing symptoms, and respiratory sinus arrhythmia in autism. J Autism Dev Disord 44: 730-737, 2014.

NEUHAUS E, BERNIER RA, BEAUCHAINE TP: Children with autism show altered autonomic adaptation to novel and familiar social partners. Autism Res 9: 579-591, 2016.

O'HAIRE ME, MCKENZIE SJ, BECK AM, SLAUGHTER V: Animals may act as social buffers: skin conductance arousal in children with autism spectrum disorder in a social context. Dev Psychobiol 57: 584-595, 2015.

OSTATNIKOVA D, PIVOVARCIOVA A, DURDIAKOVA J, HNILICOVA S, BABINSKA K: Autism - current research and social problem (in Slovak). Psychiatria-psychoterapia-psychosomatika 22: 20-25, 2015.

PALKOVITZ RJ, WIESENFELD AR: Differential autonomic responses of autistic and normal children. $J$ Autism Dev Disord 10: 347-360, 1980.

PANJU S, BRIAN J, DUPUIS A, ANAGNOSTOU E, KUSHKI A: Atypical sympathetic arousal in children with autism spectrum disorder and its association with anxiety symptomatology. Mol Autism 6: 64, 2015.

PATRIQUIN MA, SCARPA A, FRIEDMAN BH, PORGES SW: Respiratory sinus arrhythmia: a marker for positive social functioning and receptive language skills in children with autism spectrum disorders. Dev Psychobiol 55: 101-112, 2013.

PORGES SW: Orienting in a defensive world: mammalian modifications of our evolutionary heritage. A Polyvagal Theory. Psychophysiology 32: 301-318, 1995.

PORGES SW: The Polyvagal Theory: phylogenetic contributions to social behavior. Physiol Behav 79: 503-513, 2003.

PORGES SW, MACELLAIO M, STANFILL SD, MCCUE K, LEWIS GF, HARDEN ER, HANDELMAN M, DENVER J, BAZHENOVA OV, HEILMAN KJ: Respiratory sinus arrhythmia and auditory processing in autism: modifiable deficits of an integrated social engagement system? Int J Psychophysiol 88: 261-270, 2013.

PURCELL AE, JEON OH, ZIMMERMAN AW, BLUE ME, PEVSNER J: Postmortem brain abnormalities of glutamate transmitter system in autism. Neurology 57: 1618-1628, 2001.

SCHAAF RC, BENEVIDES TW, LEIBY BE, SENDECKI JA: Autonomic dysregulation during sensory stimulation in children with autism spectrum disorder. J Autism Dev Disord 45: 461-472, 2015.

SCHULTZ RT: Developmental deficits in social perception in autism: the role of the amygdala and fusiform face area. Int J Dev Neurosci 23: 125-141, 2005.

SCHUMANN CM, HAMSTRA J, GOODLIN-JONES BL, LOTSPEICH LJ, KWON H, BUONOCORE MH, LAMMERS CR, REISS AL, AMARAL DG: The amygdala is enlarged in children but not adolescents with autism; the hippocampus is enlarged at all ages. J Neurosci 24: 6392-6401, 2004.

SCHUMANN CM, BARNES CC, LORD C, COURCHESNE E: Amygdala enlargement in toddlers with autism related to severity of social and communication impairments. Biol Psychiatry 66: 942-949, 2009.

SNOEK H, VAN GOOZEN SH, MATTHYS W, BUITELAAR JK, VAN ENGELAND H: Stress responsivity in children with externalizing behavior disorders. Dev Psychopathol 16: 389-406, 2004. 
SPARKS BF, FRIEDMAN SD, SHAW DW, AYLWARD EH, ECHELARD D, ARTRU AA, MARAVILLA KR, GIEDD JN, MUNSON J, DAWSON G, DAGER SR: Brain structural abnormalities in young children with autism spectrum disorder. Neurology 59: 184-192, 2002.

STONER R, CHOW ML, BOYLE MP, SUNKIN SM, MOUTON PR, ROY S, WYNSHAW-BORIS A, COLAMARINO SA, LEIN ES, COURCHESNE E: Patches of disorganization in the neocortex of children with autism. N Engl J Med 370: 1209-1219, 2014.

TASK FORCE OF THE EUROPEAN SOCIETY OF CARDIOLOGY AND THE NORTH AMERICAN SOCIETY OF PACING AND ELECTROPHYSIOLOGY: Heart rate variability. Standards of measurement, physiological interpretation, and clinical use. Eur Heart J 17: 354-381, 1996.

THAYER JF, LANE RD: Claude Bernard and the heart-brain connection: further elaboration of a model of neurovisceral integration. Neurosci Biobehav Rev 33: 81-88, 2009.

THAYER JF, STERNBERG E: Beyond heart rate variability: vagal regulation of allostatic systems. Ann N Y Acad Sci 1088: 361-372, 2006.

TONHAJZEROVA I, ONDREJKA I, JAVORKA K, CALKOVSKA A, JAVORKA M: Cardiac vagal control in depression and attention deficit/hyperactivity disorder. Acta Med Mart 11: 46-51, 2011.

TONHAJZEROVA I, ONDREJKA I, TURIANIKOVA Z, JAVORKA K, CALKOVSKA A, JAVORKA M: Heart rate variability: an index of brain-heart interaction. In: Tachycardia. T YAMADA (ed), InTech, Rijeka, 2012 , pp 185-202.

UDDIN LQ, MENON V: The anterior insula in autism: under-connected and under-examined. Neurosci Biobehav Rev 33: 1198-1203, 2009.

VETRUGNO R, LIGUORI R, CORTELLI P, MONTAGNA P: Sympathetic skin response: basic mechanisms and clinical applications. Clin Auton Res 13: 256-270, 2003.

WANG Y, HENSLEY MK, TASMAN A, SEARS L, CASANOVA MF, SOKHADZE EM: Heart rate variability and skin conductance during repetitive TMS course in children with autism. Appl Psychophysiol Biofeedback 41: 47-60, 2016.

YAMAMOTO Y, HUGHSON RL: Coarse-graining spectral analysis: new method for studying heart rate variability. J Appl Physiol 71: 1143-1150, 1991. 